Movere Journal Vol 2 No. 2 Juli 2020 Hal 20 - 31

MOVERE JOURNAL

http://ojs.stie-tdn.ac.id/index.php/mv

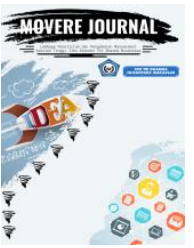

\title{
PENGARUH TANGIBLE DAN RESPONSIVENESS TERHADAP KEPUASAN PASIEN PADA RSUD LAMADDUKELLENG KABUPATEN WAJO
}

\author{
Asnidar, Akbar, Nurjaya \\ IAIN Parepare, STIE Lamaddukelleng, STIE Tri Dharma Nusantara \\ E-mail : asnidar@iainpare.ac.id, akbar.pattola0021@gmail.com, \\ nurjaya.gani@gmail.com
}

\begin{abstract}
Abstrak: Penelitian ini ditujukan untuk mengetahui apakah kualitas pelayanan yang diberikan oleh RSUD Lamaddukelleng Kabupaten Wajo bisa memberikan kepuasan bagi para pasiennya. Populasi dalam penelitian adalah pasien rawat inap pada RSUD Lamaddukelleng dalam tiga bulan terakhir, yaitu bulan Januari - Maret 2017 berjumlah 5.018 orang. Penentuan jumlah sampel menggunakan rumus slovin sehingga diperoleh jumlah sampel sebanyak 370 responden. Sampel diambil dengan menggunakan teknik simple random sampling. Data diuji dengan menggunakan analisis regresi linier berganda. Pengujian data menggunakan SPSS 22. Peneliti juga menggunakan uji validitas dan uji reliabilitas untuk kuesioner. Untuk pengujian hipotesis menggunakan koefisien determinasi, uji simultan dan uji parsial. Hasil penelitian menunjukan bahwa tangible dan responsiveness secara simultan berpengaruh signifikan terhadap kepuasan pasien (nilai $\mathrm{F}_{\text {hitung }}>\mathrm{F}_{\text {tabel }}$ yaitu $19,731>3,020$ dan signifikasi $\mathrm{t}=0,000<0,05)$. Secara parsial tangible mempunyai pengaruh positif dan signifikan terhadap kepuasan pasien rawat inap (nilai $t_{\text {hitung }}>t_{\text {tabel }}$ yaitu 2.103>1.649 dan signifikasi $\mathrm{t}=0,036<0,05)$. Responsiveness mempunyai pengaruh positif dan signifikan terhadap kepuasan pasien rawat inap (nilai $t_{\text {hitung }}>t_{\text {tabel }}$ yaitu 2.610 $>1.649$ dan signifikasi $\mathrm{t}=0,009<0,05)$.
\end{abstract}

Kata Kunci: Tangible; Responsiveness; Kepuasan Pasien

Abstract: This research aims at finding out whether the service quality given by regional public hospital of Lamaddukelleng Wajo Regency can give satisfaction for their patient. The population of this research was inpatients of regional public hospital of Lamaddukelleng for the past three month namely January to March 2017, it is 5.018 people. The sample was determined by using Slovin formula so it was obtained the sample 370 respondents. The sample was taken by using sampling random simple technique. The data was tested by using analysis of multiple linear regression. The testing of data used SPSS 22. The researcher also used validity and 
reliability test for questionnaire. For hypothesis test, it used determination coefficient, simultaneous test, and partial test. The result of the research shows that the tangible and responsiveness simultaneously influence the satisfaction of patient significantly (value of Fhitung $>$ Ftabel it is 19,731>3,020 and significance $t=0,000<0,05$ ). Partially, tangible has positive effect and it is significance to the satisfaction of inpatients (the value of thitung>ttabel is $2.103>1.649$ and significance $t=$ 0,036<0,05). Responsiveness has effect and it is significance to the satisfaction of inpatients (the value of thitung $>$ ttabel it is 2.610>1.649 and significance $t=$ $0,009<0,05)$.

\section{PENDAHULUAN}

Pada era globalisasi ini persaingan sangatlah tajam baik itu di pasar domestik ataupun pasar internasional. Agar dapat berkembang atau paling tidak dapat bertahan perusahaan harus dapat menghasilkan produk barang maupun jasa dengan kualitas yang baik. Ada beberapa aktivitas dalam menciptakan kualitas yang baik, salah satu yang terpenting adalah pengendalian kualitas. Pengendalian kualitas penting dilakukan agar produk yang dihasilkan oleh perusahaan sesuai dengan standar yang telah ditetapkan perusahan dan standar yang telah ditetapkan oleh badan yang berwenang.

Fenomena globalisasi juga berdampak terhadap rumah sakit. Rumah sakit pada era globalisasi ini bukan hanya mengemban misi sosial. Aspek bisnis dalam pengelolaan suatu rumah sakit sudah menjadi suatu konsekuensi wajar pada era globalisasi. Karena itu rumah sakit tidak perlu lagi mengesampingkan upaya untuk lebih mempromosikan diri. Prasarana dan fasilitas rumah sakit serta kemajuan ilmu kedokteran perlu dijelaskan kepada masyarakat, mengingat persaingan pelayanan medis semakin ketat. Rumah sakit sebagai institusi pelayanan kesehatan yang padat modal dan sumber daya manusia membutuhkan budaya perusahaan yang baik agar sumber daya yang tersedia dimanfaatkan secara efektif dan efisien untuk mencapai tujuan yang telah ditetapkan.

Kualitas pelayanan di rumah sakit merupakan suatu fenomena yang unik sebab seseorang dalarn mempersepsikan suatu kualitas pelayanan dapat berbeda diantara orang-orang yang terlibat dalam pelayanan. Hal ini disebabkan karena kepuasan pasien merupakan hasil penilaian perasaan yang lebih bersifat subjektif. Begitupun dengan RSUD Lamaddukelleng menjadi salah satu unit bisnis pemerintah (sektor publik) yang memiliki kewajiban memberikan pelayanan kesehatan kepada masyarakat dengan optimal tanpa tujuan mencari laba (nonprofit organization). Untuk memberikan pelayanan kesehatan yang optimal seperti yang diharapkan, dibutuhkan perencanaan, pengorganisasian, pengoperasian dan pengendalian yang baik. Sebagai rumah sakit rujukan pelayanan kesehatan di era globalisasi dihadapkan pada kekuatan-kekuatan dan masalah-masalah intern yang ada, seperti terbatasnya sumber daya yang dimiliki dan inventarisasi yang belum memadai. Di lain pihak secara bersamaan juga dihadapkan pada kondisi lingkungan dengan berbagai faktor peluang dan tantangan yang senantiasa berkembang dinamis. Oleh (c) 2020 STIE TDN. All rights reserved 
karena itu, untuk dapat memberikan pelayanan kesahatan yang prima bagi masyarakat perlu disusun visi, misi, tujuan, sasaran, serta indikator keberhasilan yang diwujudkan dalam bentuk rencana strategis. Indikator keberhasilan merupakan alat ukur yang harus dievaluasi secara periodik dan berkesinambungan. Indikator bukan saja dalam bentuk finansial tapi juga dengan indikator yang lain seperti peningkatan kualitas layanan pasien, bisnis internal, juga pembelanjaran dan pertumbuhan yang selanjutnya dijadikan bahan untuk mengendalikan arah dan mutu pelayanan kesehatan agar visi yang telah ditetapkan benarbenar dapat diwujudkan.

Konsekuensi bagi RSUD yang menerapkan PPK-BLUD penuh adalah mampu mengelola pendapatan fungsional rumah sakit (pendapatan BLUD-RSUD) untuk membiayai seluruh kegiatan operasional yang berhubungan langsung dengan pemberian pelayanan kepada pasien. Untuk itu setiap potensi yang berpeluang menjadi sumber pendapatan harus dikelola dengan optimal. Pengembangan setiap jenis layanan baru sesui dengan inti bisnis rumah sakit perlu dilakukan terus menerus sepanjang tahun dengan inovasi-inovasi terkini sesuai dengan tujuan, visi dan misi yang telah di tetapkan. Pada masa mendatang, kunci utama kesuksesan rumah sakit adalah terletak pada dua hal pokok yaitu pemanfaatan sumber daya khusus rumah sakit sebagai institusi pelayanan kesehatan yang padat modal dan sumber daya manusia, membutuhkan budaya perusahaan yang baik agar sumber daya yang tersedia dimanfaatkan secara efektif dan efisien untuk mencapai tujuan yang telah ditetapkan. Kepuasan pasien merupakan salah satu upaya untuk menciptakan hubungan yang baik antara rumah sakit dengan pasien. Pasien yang memperoleh produk atau jasa yang sesuai atau melebihi harapan, cenderung akan memberikan tanggapan yang positif bagi rumah sakit.

Masalah utama suatu rumah sakit adalah apabila pasien merasa tidak puas terhadap pelayanan yang diberikan. Oleh karena itu RSUD Lamaddukelleng dituntut untuk selalu menjaga kepercayaan konsumen dengan meningkatkan kualitas pelayanan agar kepuasan konsumennya meningkat. Penelitian ini ditujukan untuk mengetahui apakah kualitas pelayanan yang diberikan oleh RSUD Lamaddukelleng bisa memberikan kepuasan bagi para pasiennya.

\section{TELAAH LITERATUR DAN PENGEMBANGAN HIPOTESIS Bukti Fisik (Tangible)}

Kualitas layanan adalah bentuk aktualisasi nyata secara fisik yang dapat dilihat oleh orang lain. Menurut Sunyoto dan Fatonah (2015:288) tangible yaitu kemampuan suatu perusahaan dalam menunjukan eksistensinya kepada pihak eksternal. Penampilan dan kemampuan sarana dan prasarana fisik perusahaan yang dapat diandalkan keadaan lingkungan sekitarnya merupakan bukti nyata dari pelayanan yang diberikan oleh pemberi jasa. Sedangkan menurut Parasuraman dkk dalam Bursan dan Chanerie (2012) tangible yaitu kemampuan suatu perusahaan dalam menunjukkan eksistensinya pada pihak eksternal. Penampilan dan kemampuan sarana dan prasarana fisik perusahaan dan keadaan lingkungan sekitarnya adalah (C) 2020 STIE TDN. All rights reserved 
bukti nyata dari pelayanan yang diberikan oleh pemberi jasa. ini meliputi fasilitas fisik (Gedung, Gudang, dan lainnya), teknologi (peralatan dan perlengkapan yang dipergunakan), serta penampilan pegawainya. Secara singkat dapat diartikan dewasa ini tuntutan perusahaan dalam melayani konsumen dengan sebaik-baiknya yang timbal balik dapat dirasakan secara langsung sudah menjadi bahan pembicaraan. Identifikasi kualitas tangible dapat tercermin dari aplikasi lingkungan kerja berupa:

1. Kemampuan menunjukkan prestasi kerja pelayanan dalam menggunakan alat dan perlengkapan kerja secara efisien dan efektif.

2. Kemampuan menunjukkan penguasaan teknologi dalam berbagai akses data dan inventarisasi otomasi kerja sesuai dengan dinamika dan perkembangan dunia kerja yang dihadapinya.

3. Kemampuan menunjukkan integritas diri sesuai dengan penampilan yang menunjukkan kecakapan, kewibawaan dan dedikasi kerja.

\section{Daya Tanggap (Responsiveness)}

Daya tanggap menurut Sunyoto dan Fatonah (2015:289) yaitu suatu kebijakan untuk membantu dan memberikan pelayanan yang cepat dan tepat kepada pelanggan, dengan penyampaian informasi yang jelas. Membiarkan konsumen menunggu persepsi yang negatif dalam kualitas pelayanan. Margaretha dalam Sahib (2012) kualitas layanan daya tanggap adalah suatu bentuk pelayanan dalam memberikan penjelasan, agar orang yang diberi pelayanan tanggap dan menanggapi pelayanan yang diterima, sehingga diperlukan adanya unsur kualitas layanan daya tanggap sebagai berikut:

1. Memberikan penjelasan secara bijaksana sesuai dengan bentuk bentuk pelayanan yang dihadapinya. Penjelasan bijaksana tersebut mengantar individu yang mendapat pelayanan mampu mengerti dan menyetujui segala bentuk pelayanan yang diterima.

2. Memberikan penjelasan yang mendetail yaitu bentuk penjelasan yang substantif dengan persoalan pelayanan yang dihadapi, yang bersifat jelas, transparan, singkat dan dapat dipertanggungjawabkan

3. Memberikan pembinaan atas bentuk - bentuk pelayanan yang dianggap masih kurang atau belum sesuai dengan syarat - syarat atau prosedur pelayanan yang ditunjukkan.

4. Mengarahkan setiap bentuk pelayanan dari individu yang dilayani untuk menyiapkan, melaksanakan dan mengikuti berbagai ketentuan pelayanan yang harus dipenuhi.

5. Membujuk orang yang dilayani apabila menghadapi suatu permasalahan yang dianggap bertentangan, berlawanan atau tidak sesuai dengan prosedur dan ketentuan yang berlaku.

\section{Kepuasan Konsumen}

Telah menjadi suatu kepercayaan umum khususnya di dunia bisnis, bahwa kepuasan konsumen merupakan salah satu kunci keberhasilan suatu usaha. Hal ini dikarenakan dengan memuaskan konsumen, organisasi dapat meningkatkan tingkat (c) 2020 STIE TDN. All rights reserved

Corresponding Author: 
keuntungannya dan mendapatkan pangsa pasar yang lebih luas. Karena kepuasan merupakan faktor penting maka banyak studi dilakukan untuk mengukur kepuasan konsumen, sehingga banyak definisi dari kepuasan konsumen.

Kotler dan Keller (2007) mendefinisikan kepuasan konsumen adalah "Customer satisfaction is the level of a person's felt state resultating from comparing a product's perceived performance (or outcome) in relation to the person's expectation". Kepuasan konsumen adalah tingkat perasaan seseorang sebagai hasil dari perbandingan antara kenyataan dan harapan yang diterima dari sebuah produk atau jasa. Bila kinerja produk jauh lebih rendah dibandingkan harapan pelanggan, pembelinya tidak puas. Bila kinerja sesuai harapan atau melebihi harapan, pembelinya merasa puas atau merasa sangat gembira.

Kepuasan konsumen hanya dapat tercapai dengan memberikan pelayanan yang berkualitas kepada konsumennya. Layanan yang baik sering dinilai oleh konsumen secara langsung, karena itu diperlukan usaha untuk meningkatkan kualitas sistem pelayanan yang diberikan agar dapat memenuhi keinginan dan meningkatkan kepuasan konsumen. Jadi kualitas pelayanan merupakan hal penting yang harus diperhatikan oleh perusahaan agar dapat tercapai kepuasan konsumen. Kepuasan konsumen akan terpenuhi apabila proses penyampaian jasa dari si pemberi jasa kepada konsumen sesuai dengan apa yang dipersepsikan konsumen. Karena berbagai faktor, seperti subjektivitas yang dipersepsikan konsumen dan pemberi jasa, maka jasa sering disampaikan dengan cara yang berbeda dengan yang dipersepsikan konsumen.

\section{Kerangka Konseptual}

Berdasarkan uraian yang telah dikemukakan sebelumnya, maka pada bagian ini diuraikan kerangka berpikir yang dijadikan landasan berpikir dalam melaksanakan penelitian. Berdasarkan pernyataan di atas maka kerangka pikir penelitian ini dapat digambarkan seperti berikut:

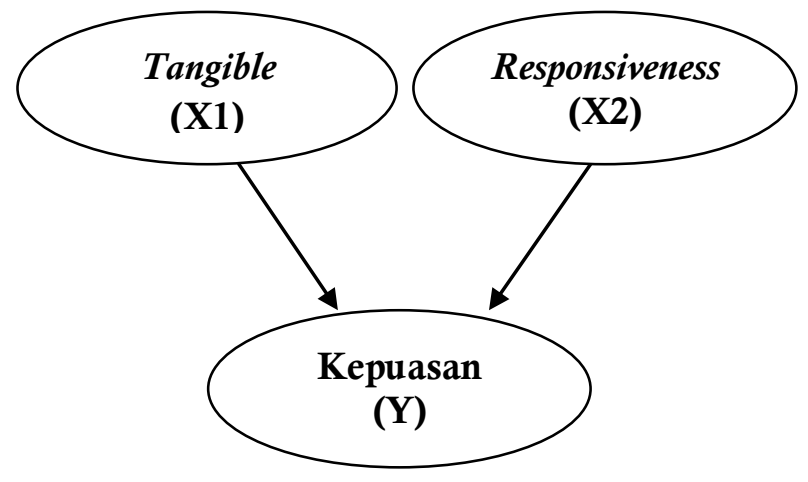

\section{Hipotesis} adalah:

Hipotesis dalam penelitian ini

1. Tangible berpengaruh secara positif dan signifikan terhadap kepuasan.

2. Responsiveness berpengaruh secara positif dan signifikan terhadap kepuasan.

\section{METODE PENELITIAN}

\section{Jenis Penelitian}

Jenis penelitian ini merupakan penelitian kualitatif yaitu penelitian tentang data yang berupa penjelasanpenjelasan mengenai kualitas pelayanan terhadap kepuasan pasien pada RSUD Lamaddukelleng. Dan berupa data kuantitatif sebagai pendukungnya, data yang berbentuk angka-angka dan dapat dihitung dengan satuan hitung. Dalam hal ini, data kuantitatif yang digunakan adalah (C) 2020 STIE TDN. All rights reserved

Corresponding Author: 
jawaban responden atas kuesioner yang diajukan.

\section{Sumber Data}

1. Data Primer adalah data yang diperoleh peneliti langsung dari sumbernya berupa informasi terkait dengan penelitian ini. Data primer dalam penelitian ini adalah jawaban responden dari kuesioner dan wawancara mengenai kualitas pelayanan terhadap kepuasan.

2. Data Sekunder adalah data yang berupa dokumen-dokumen yang telah dikumpulkan dan telah diolah pihak-pihak terkait sehingga dapat digunakan untuk kepentingan analisis data. Data sekunder dalam penelitian ini berupa penelitian terdahulu, jurnal ilmiah, literatur yang terkait, dan data kelengkapan lainnya.

\section{Populasi dan sampel}

Populasi dalam penelitian adalah pasien rawat inap pada RSUD Lamaddukelleng Kabupaten Wajo. Menurut informasi yang di dapatkan dari staf bagian pelayanan dalam tiga bulan terakhir, yaitu bulan JanuariMaret 2017 berjumlah 5.018 orang pasien.

Penentuan jumlah sampel menggunakan rumus slovin sehingga diperoleh jumlah sampel sebanyak 370 responden. Sampel diambil dengan menggunakan teknik simple random sampling.

\section{Teknik Analisis}

Data diuji dengan menggunakan analisis regresi linier berganda. Pengujian data menggunakan SPSS 22. Peneliti juga menggunakan uji validitas dan uji reliabilitas untuk kuesioner. Uji asumsi klasik yang digunakan adalah uji multikoliniaritas, uji normalitas, uji heteroskedastisitas dan uji autokorelasi. Untuk pengujian hipotesis menggunakan koefisien determinasi, uji simultan dan uji parsial.

\section{HASIL DAN PEMBAHASAN Uji Validitas dan Realibilitas}

Uji validitas dilakukan untuk setiap variabel laten yang dikontruksi oleh indikator-indikatornya masingmasing. Uji validitas adalah merujuk kepada sejauh mana suatu uji dapat mengukur apa yang sebenarnya ingin diukur. Uji validitas menggunakan rumus The Product Moment Coeffisient corelation yaitu dengan melihat letak masing-masing item pertanyaan dibandingkan dengan $r_{\text {tabel }}$ pada tingkat signifikan $5 \%$ dan $\mathrm{df}=\mathrm{n}-2$, yaitu sebesar $370-2=368$ dengan menggunakan SPSS 22 diperoleh nilai $\mathrm{r}_{\text {tabel }}$ sebesar 0,101. maka apabila $r_{\text {hitung }}>r_{\text {tabel, }}$ maka item pertanyaan tersebut dinyatakan valid.

Tabel 1. Hasil Uji validitas item pertanyaan untuk variabel Tangible $\left(\mathrm{X}_{1}\right)$

\begin{tabular}{|c|c|c|c|}
\hline Item Pertanyaan & Koefisien Korelasi (r) & r tabel & Keterangan \\
\hline $\mathrm{X}_{1} \cdot 1$ & 0,739 & & Valid \\
\hline $\mathrm{X}_{1} \cdot 2$ & 0,801 & \multirow{4}{*}{0,101} & Valid \\
\hline $\mathrm{X}_{1} \cdot 3$ & 0,688 & & Valid \\
\hline $\mathrm{X}_{1} \cdot 4$ & 0,779 & & Valid \\
\hline $\mathrm{X}_{1} \cdot 5$ & 0,830 & & Valid \\
\hline $\mathrm{X}_{1} \cdot 6$ & 0,806 & & Valid \\
\hline
\end{tabular}




\begin{tabular}{|l|l|l|l|}
\hline $\mathrm{X}_{1} .7$ & 0,738 & & Valid \\
\hline
\end{tabular}

Tabel 2. Hasil Uji validitas item pertanyaan untuk variabel Responsiveness $\left(\mathrm{X}_{2}\right)$

\begin{tabular}{|c|c|c|c|}
\hline Item Pertanyaan & Koefisien Korelasi (r) & r tabel & Keterangan \\
\hline$X_{1} \cdot 1$ & 0,739 & & Valid \\
\hline$X_{1} \cdot 2$ & 0,801 & \multirow{4}{*}{0,101} & Valid \\
\hline$X_{1} \cdot 3$ & 0,688 & & Valid \\
\hline$X_{1} \cdot 4$ & 0,779 & & Valid \\
\hline$X_{1} \cdot 5$ & 0,830 & & Valid \\
\hline$X_{1} \cdot 6$ & 0,806 & Valid \\
\hline$X_{1} \cdot 7$ & 0,738 & Valid \\
\hline
\end{tabular}

Tabel 3. Hasil Uji validitas item pertanyaan untuk variabel Kepuasan Pasien (Y)

\begin{tabular}{|c|c|c|c|}
\hline Item Pertanyaan & Koefisien Korelasi $(\mathbf{r})$ & $\mathbf{r}$ tabel & Keterangan \\
\hline $\mathrm{X}_{1} \cdot 1$ & 0,739 & & Valid \\
\hline $\mathrm{X}_{1} \cdot 2$ & 0,801 & \multirow{4}{*}{0,101} & Valid \\
\hline $\mathrm{X}_{1} \cdot 3$ & 0,688 & & Valid \\
\hline $\mathrm{X}_{1} \cdot 4$ & 0,779 & & Valid \\
\hline $\mathrm{X}_{1} \cdot 5$ & 0,830 & & Valid \\
\hline $\mathrm{X}_{1} \cdot 6$ & 0,806 & & Valid \\
\hline $\mathrm{X}_{1} \cdot 7$ & 0,738 & & Valid \\
\hline
\end{tabular}

Uji realibilitas dalam penelitian ini dilakukan dengan cara mencobakan instrumen sekali saja, dan dari data yang diperoleh dianalisis dengan tertentu. Teknik reliabilitas semacam ini disebut Interbal Consistency. Karena dalam penelitian ini jawaban dari instrumen bersifat berjenjang atau tidak bersifat dikotomi (mempunyai dua alternatif jawaban) maka digunakan teknik pengujian dengan metode Alpha Cronbach. Dalam melakukan perhitungan Alpha, digunakan alat bantu program komputer yaitu SPSS 22. Sedangkan dalam pengambilan keputusan reliabilitas, suatu instrumen dikatakan reliabel jika nilai alpha lebih besar dari 0,60 .

Tabel 4. Hasil Uji Reliabilitas Variabel Penelitian

\begin{tabular}{|c|c|c|c|}
\hline Variabel & Alpha Cronbach & \multirow{2}{*}{ Kriteria } & Keterangan \\
\hline Tangible $\left(\mathrm{X}_{1}\right)$ & 0,787 & & Reliable \\
\cline { 1 - 2 } & 0,787 & \multirow{2}{*}{0.60} & Reliable \\
\cline { 1 - 2 } Responsiveness $\left(\mathrm{X}_{2}\right)$ & 0,783 & Reliable \\
\hline
\end{tabular}

\section{Analisis Regresi Linier Berganda}

Analisis regresi linier berganda dalam penelitian ini bertujuan untuk 
melihat ketepatan prediksi variabel independen tangible $\left(\mathrm{X}_{1}\right)$ dan responsiveness $\left(\mathrm{X}_{2}\right)$ terhadap variabel dependen kepuasan pasien (Y) pada RSUD Lamaddukelleng. Menurut Hasan
(2012 : 269) persamaan regresi linier berganda adalah sebagai berikut:

$$
\mathrm{Y}=\mathrm{a}+\mathrm{b}_{1} \mathrm{X}_{1}+\mathrm{b}_{2} \mathrm{X}_{2}+\mathrm{e}
$$

Model persamaan regresi linier berganda dalam penelitian ini ada sebagai berikut:

Tabel 5. Hasil Regressi Linier Berganda

Coefficients $^{\mathrm{a}}$

\begin{tabular}{|ll|r|r|}
\hline \multirow{2}{*}{ Model } & \multicolumn{2}{|c}{$\begin{array}{c}\text { Unstandardized } \\
\text { Coefficients }\end{array}$} \\
\cline { 3 - 4 } & & \multicolumn{1}{|c}{ B } & Std. Err \\
\hline 1 & (Constant) & 8.598 & \\
& X1 & .134 & \\
& X2 & .155 & \\
& &
\end{tabular}

Hasil perhitungan dapat dijelaskan sebagai berikut: Tabel 5 dapat dibuat persamaan regresi linier berganda yang digunakan adalah sebagai berikut:

$\mathrm{Y}=8,598+0,134 \mathrm{X}_{1}+0,155 \mathrm{X}_{2}$

Interpretasi hasil persamaan regresi linier berganda:

$\begin{aligned} \mathrm{a}= & \text { Konstanta sebesar } \\ & \text { artinya bahwa jika variabel } \\ & \text { tangible, dan responsiveness } \\ & \text { tidak ada perubahan atau } \\ & \text { konstan maka kepuasan pasien } \\ & \text { RSUD Lamaddukelleng positif. } \\ \mathrm{b}_{1} \mathrm{X}_{1}= & \text { Koefisien regresi variabel } \\ & \text { tangible (bukti fisik) sebesar } \\ & \text { 0,134, artinya bahwa variabel } \\ & \text { tangible berpengaruh positif } \\ & \text { terhadap kepuasan pasien } \\ & \text { RSUD Lamaddukelleng. Hal ini } \\ & \text { menunjukkan apabila bukti fisik } \\ & \text { ditingkatkan, maka kepuasan } \\ & \text { pasien juga akan meningkat. }\end{aligned}$

\begin{tabular}{|r|r|r|r|} 
& $\begin{array}{c}\text { Standardized } \\
\text { Coefficients }\end{array}$ & \multicolumn{1}{|c|}{} & \multicolumn{1}{c|}{ Sig. } \\
\hline 2.825 & & 3.044 & .003 \\
.064 & .113 & 2.103 & .036 \\
.059 & .133 & 2.610 & .009 \\
\hline
\end{tabular}

$\mathrm{b}_{2} \mathrm{X}_{2}=\mathrm{b}_{3} \mathrm{X}_{3}=$ Koefisien regresi variabel responsiveness (daya tanggap) sebesar 0,155 , artinya bahwa variabel daya tanggap berpengaruh positif terhadap kepuasan pasien. Hal ini menunjukkan apabila daya tanggap ditingkatkan, maka kepuasan pasien RSUD Lamaddukelleng juga akan meningkat.

\section{Uji Hipotesis}

Uji t dalam penelitian ini digunakan untuk mengetahui pengaruh yang signifikan secara individu variabel bebas (X) yaitu tangible dan responsiveness terhadap variabel terikat (Y) kepuasan pasien rawat inap di RSUD lamaddukelleng. Dapat dilihat pada tabel hasil uji berikut ini:

\section{Tabel 6. Hasil Uji t}




\begin{tabular}{|c|c|c|c|}
\hline Variabel & $\mathbf{t}-$ hitung & $\mathbf{t}$ - tabel & Sig. \\
\hline Tangible $\left(\mathrm{X}_{1}\right)$ & 2,103 & \multirow{2}{*}{1,649} & 0,036 \\
\cline { 1 - 2 } Responsiveness $\left(\mathrm{X}_{3}\right)$ & 2,610 & & 0,009 \\
\hline
\end{tabular}

Hasil perhitungan dapat dijelaskan sebagai berikut:

1. Uji t atau parsial terhadap variabel Bukti fisik $\left(\mathrm{X}_{1}\right)$ didapatkan $\mathrm{t}_{\text {hitung }}$ sebesar 2,103 lebih besar dari $t_{\text {tabel }}$ 1,649 atau dari signifikansi sebesar 0,036 lebih kecil dari $\alpha=0,05$ maka secara parsial variabel Bukti fisik $\left(\mathrm{X}_{1}\right)$ berpengaruh signifikan terhadap variabel Kepuasan Pasien (Y). Sehingga dapat disimpulkan bahwa bukti fisik yang semakin baik, akan memberikan kepuasan pasien.

2. Uji t atau parsial terhadap variabel daya tanggap $\left(\mathrm{X}_{2}\right)$ didapatkan $\mathrm{t}_{\text {hitung }}$ sebesar 2,610 lebih besar dari $t_{\text {tabel }}$ 1,649 atau dari signifikansi sebesar
0,009 lebih kecil dari $\alpha=0,05$ maka secara parsial variabel daya tanggap $\left(\mathrm{X}_{2}\right)$ berpengaruh signifikan terhadap variabel kepuasan pasien (Y). Sehingga dapat disimpulkan bahwa daya tanggap yang semakin baik, akan memberikan kepuasan pasien.

Uji $F$ digunakan untuk mengetahui secara bersama-sama "simultan" pengaruh variabel bebas (tangible dan responsiveness) terhadap variabel terikat (kepuasan pasien). Signifkan pengaruh positif dapat diestimasi dengan membandingkan dan Pvalue $\alpha=0,05$ atau $F_{\text {hitung dan }} F_{\text {tabel }}$. Berikut ini perhitungan statistic anova uji $\mathrm{F}$ dapat dilihat pada tabel berikut:

\section{Tabel 7. Hasil Uji F ANOVA $^{b}$}

\begin{tabular}{|rl|r|r|r|r|r|}
\hline \multicolumn{2}{|l|}{ Model } & \multicolumn{1}{|c|}{$\begin{array}{c}\text { Sum of } \\
\text { Squares }\end{array}$} & df & \multicolumn{1}{c|}{$\begin{array}{c}\text { Mean } \\
\text { Square }\end{array}$} & F & Sig. \\
\hline 1 & Regression & 5.976 & 2 & 2.988 & 19.731 & $.000^{\mathrm{a}}$ \\
& Residual & 55.576 & 367 & 151 & & \\
& Total & 61.552 & 369 & & & \\
\hline
\end{tabular}

Tabel 7 diatas menunjukkan variabel bebas yaitu tangible dan responsiveness secara simultan berpengaruh terhadap variabel terikat kepuasan pasien RSUD Lamaddukelleng. Hasil ini dapat dilihat dari nilai $F_{\text {hitung }}$ sebesar $19.731>F_{\text {tabel }}$ 3,020 dengan nilai signifikansi sebesar $0,000<\alpha=0,05$. Hasil ini menunjukkan bahwa variabel yaitu tangible dan responsiveness secara simultan berpengaruh terhadap Kepuasan pasien RSUD Lamaddukelleng sehingga apabila variabel tangible dan responsiveness meningkat maka kepuasan pasien juga akan meningkat demikian pula sebaliknya.

\section{Pembahasan}




\section{Pengaruh tangible terhadap kepuasan pasien}

Berwujud diartikannya sebagai tampilan fisik. Dimensi ini biasanya digunakan oleh perusahaan untuk menaikan image dimata konsumen yang dapat di gambarkan dengan kebersihan ruangan. Kondisi fisik pada umumnya akan memberikan gambaran bagaimana rumah sakit tersebut dapat berpotensi menunjukkan fungsinya sebagai tempat pelayanan kesehatan. Pada umumnya seseorang akan memandang suatu potensi rumah sakit tersebut awalnya dari kondisi fisik. Dengan kondisi yang bersih, rapi dan teratur, orang akan menduga bahwa rumah sakit tersebut akan melaksanakan fungsinya dengan baik.

Berdasarkan hasil penelitian di RSUD Lamaddukelleng yang dianalisis dengan menggunakan analisis regresi linier berganda menunjukkan bahwa tangible mempunyai pengaruh positif dan signifikan terhadap kepuasan pasien rawat inap (nilai $t_{\text {hitung }}>t_{\text {tabel }}$ yaitu $2.103>$ 1.649 dan signifikasi $\mathrm{t}=0,036<0,05)$.

Penelitian ini sejalan dengan hasil penelitian danang wahyudi (2015) yang menyatakan bahwa tangible memiliki hubungan signifikansi dengan kepuasan pasien. Begitupula hasil penelitian Budi poniman dan Supriono (2009) yang juga menyatakan bahwa tangible memiliki pengaruh yang positif dan signifikan terhadap kepuasan pasien.

Menurut Betsey dalam sutojo (2003) bahwa seorang pelanggan yang kecewa akan menceritakan kekecewaannya kepada 9 sampai 20 orang yang dikenalnya. Menurut Soeroso (2003) keberhasilan sebuah organisasi sangat tergantung pada kemampuan manajemen dalam menyerasikan unsur-unsur karyawan dengan sistem, struktur organisasi. teknologi, tugas, budaya organisasi, dan lingkungan.

Bila pasien merasa nyaman dengan layanan sebuah rumah sakit maka kenyarnanan akan mempengaruhi kualitas pelayanan dan kepuasan pasien, sehingga mendorong pasien untuk datang berobat kembali. Kenyamanan dan kenikmatan dapat menimbulkan seseorang loyal untuk datang berobat kembali guna mendapatkan pelayanan kesehatan yang sama, (Pohan, 2007)

Pengaruh responsiveness terhadap kepuasan pasien

Responsiveness adalah kesediaan untuk membantu pelanggan dan memberikan dengan segera dan tepat. Dimensi ini menekankan pada perhatian dan ketepatan dalam menghadapi permintaan, pertanyaan, keluhan serta kesulitan pelanggan. Rumah sakit merupakan lokasi yang secara umum merupakan tempat seseorang untuk mendapatkan pelayanan kesehatan. Oleh karena itu penyedia jasa pelayanan kesehatan harus mampu menanggap, setiap keluhan pasien. Dengan demikian daya tanggap yang tinggi dari pihak pengelola rumah sakit akan memberikan rasa kepercayaan pada pasien bahwa mereka akan selalu tertolong

Berdasarkan hasil penelitian di RSUD Lamaddukelleng yang dianalisis dengan menggunakan analisis regresi linier berganda juga menunjukkan bahwa responsiveness mempunyai pengaruh positif dan signifikan terhadap kepuasan pasien rawat inap (nilai $t_{\text {hitung }}>t_{\text {tabel }}$ yaitu $2.610>1.649$ dan signifikasi $t=0,009<$ $0,05)$ 
Penelitian ini sejalan dengan penelitian danang wahyudi (2015) yang menyatakan bahwa ketanggapan memiliki hubungan yang signifikan terhadap kepuasan pasien. Begitu pula dengan hasil penelitian poniman dan supriono (2009) yang juga menyatakan bahwa ketanggapan memiliki pengaruh yang positif dan signifikan terhadap kepuasan pasien. Menurut Parasuraman (1990) dan Tjiptono (2005) yang menyatakan bahwa perhatian bagian dari dimensi mutu pelayanan yang berpengaruh terhadap keputusan dalam menggunakan jasa pelayanan.

\section{KESIMPULAN}

Dari hasil pengujian hipotesis dengan menggunakan uji regresi berganda maka dapat ditarik simpulan sebagai berikut:

1. Hasil pengujian menunjukkan bahwa hipotesis pertama yang diajukan dalam penelitian ini terbukti, ini berarti bahwa tangible berpengaruh positif dan signifikan terhadap kepuasan pasien rawat inap RSUD Lamaddukelleng.

2. Hasil pengujian menunjukkan bahwa hipotesis kedua yang diajukan dalam penelitian ini terbukti, ini berarti bahwa responsiveness berpengaruh positif dan signifikan terhadap kepuasan pasien rawat inap RSUD Lamaddukelleng.

3. Sementara hasil pengujian secara simultan menunjukkan bahwa dari dua variabel tersebut yaitu variabel tangible dan responsiveness, sistem pengukuran pelayanan mempunyai pengaruh yang kuat terhadap kepuasan Pasien. Secara parsial, variable responsiveness yang memiliki pengaruh paling dominan terhadap kepuasan pasien rawat inap di RSUD Lamaddukelleng.

\section{Daftar Pustaka}

Akbar , M. Muzahid and Parvez, Noorjahan. (2009) Impact of Service Quality, Trust and Customer satisfaction on Consumer Loyalty. ABC Journal. Vol.29, No. 1, pp. 24 -38 .

Azwar, (2006). Menjaga mutu pelayanan kesehatan aplikasi prinsip lingkaran pemecahan masalah.Jakarta :Pustaka sinar harapan

Barney, (1991) Firm Resource abd Sustained Competitive Advantage, Journal of Management, Vol 17. N0. 1, Texas A \& M University.

Budi poniman dan supriyono (2009) pengaruh kualitas pelayanan terhadap kepuasan pelanggan. Studi pada pelanggan Restoran Ayam Penyet Ria Felita Semarang. Jurnal Manajemen Pemasaran

Ferdinand, (2006) Populasi dan sampel, sampel diambil dengan menggunakan salah satu metode dalam probability sampling yaitu simple random sampling

Fornel, (1992) “A National Customer Satisfaction Barometer : The Swedish Experience", Journal of Marketing.

Kotler , P. dan Keller , K.L. (2007) Manajemen Pemasaran, Edisi Kedua Belas Jilid 1. Edisi Bahasa Inggris. Pearson Education, Inc. Upper Saddler River, New Jersey, 07458, Edisii Bahasa Indonesia, 
pada PT. INDEKS, Manajemen Pemasaran, Edisi Kedua Belas Jilid 1. Edisi Bahasa Inggris. Pearson Education, Inc. Upper Saddler River, New Jersey, 07458, Edisii Bahasa Indonesia, pada PT. INDEKS.

Kotler (2002) Manajemen pemasaran, edisi melinium,jilid 2, Jakarta : Pearson Education Asia dan PT. Prehalindo

Manullang, Ida. (2008) Pengaruh Kualitas Pelayanan Terhadap Kepuasan Pelanggan Jasa Penerbangan PT. Garuda Indonesia Airliner di Bandara Polonia Medan. Tesis, Sekolah Pasca Sarjana Universitas Sumatra Utara, Medan.

Oliver, Sandra. (2007) Strategi Public Relations. Jakarta : Penerbit Erlangga.

Parasuraman, A., Berry, L.L. and Zeithmal, V.A. (1985) A Conceptual ,Model of Service Quality and Its Implication for Future Research, Journal of Marketing, Vol. 49, pg. 41.

Parasuraman, A., Zeithaml, V.A. and Berry, L.L. (1988) SERVQUAL: A Multiple Item Scale For Measuring Consumer Perceptions Of Service Quality. Journal of Retailing. Vol. 64 No. 1, pp. 14-40.

Pohan, (2007) Jaminan mutu kesehatan : dasar-dasar penerapan.jakarta : EGC

Rahayu Triastity dan SL Trianingsih (2009) Pengaruh kualitas pelayanan terhadap kepuasan. (Studi pada
Konsumen rumah di CV satria Graha gedongan,colomadu karanganyar). Jurnal Manajemen Pemasaran.

Sugiyono, (2008) Metode Penelitian Bisnis. Bandung : Penerbit Alfabeta

Sugiyono (2005). Metode Slovin Bandung : Penerbit Alfabeta

Tjiptono, F. dan Chandra, G. (2007) Service Quality \& Satisfaction. Yogyakarta : Penerbit ANDI

Tjiptono, Fandy. (1997) Prinsip - prinsip Total Quality Service (TQS). Yogyakarta : Penerbit ANDI.

Viona Aprilia (2009) Pengaruh dimensi kualitas pelayanan terhadap kepuasan pelanggan. (Studi pada pelanggan J.co cabang Padang) Jurnal Manajemen pemasaran.

Wahyudi (2015), analisis pengaruh kualitas pelayanan rumah sakit terhadap kepuasan pasien. (Studi pada pasien provinsi daerah istimewa yogyakarta).Jurnal Manajemen Pemasaran

Zeithmal, Valarie. A., Berry, Leonard. L., and Parasuraman, A. (1996) The Behavioral Consequences of Service Quality. Journal of Marketing. Vol . 60, pp . $31-46$.

Zurni zahar samosir (2005) Pengaruh kualitas pelayanan terhadap kepuasan.( (Studi pada mahaswa dalam menggunakan perpustakaan USU). Jurnal Manajemen Pemasaran. 